\title{
Perancangan Sistem Login Pada Aplikasi Berbasis GUI Menggunakan QTDesigner Python
}

\author{
Dias Ayu Budi Utami \\ Universitas AMIKOM Purwokerto \\ dias@amikompurwokerto.ac.id
}

\begin{abstract}
Advances in technology are increasingly making applications have increasingly sophisticated quality. Various programming languages also take part in building various applications with various types of platforms. One type of desktop application. Currently, desktop platform applications can be built using a variety of programming languages. One of them is the python programming language. The python programming language has several advantages, namely: the python programming language is simple and flexible so that it is easy to develop (reusable), desktop applications generated using python are dynamic and eventbased which makes the application responsive. Making desktop applications using python is easier with the QtDesigner, namely classes in the python programming language that are event handlers that are suitable for desktop applications. One example of a GUI application that will be created using QtDesigner based on the python programming language is the login system in the application.
\end{abstract}

Keywords: Login; GUI; Python; Event Handler; QtDesigner

\begin{abstract}
Abstrak
Kemajuan Teknologi semakin membuat aplikasi mempunyai kualitas yang semakin canggih. Berbagai bahasa pemrograman turut mengambil peran dalam membangun berbagai aplikasi dengan jenis platform yang beragam. Salah satunya jenis aplikasi GUI. Saat ini, aplikasi berplatform GUI (Grapichal User Interface) dapat dibangun menggunakan berbagai macam bahasa pemrograman. Salah satunya yaitu bahasa pemrograman python. Bahasa pemrograman python memiliki beberapa keunggulan yaitu : bahasa pemrograman python bersifat sederhana dan fleksibel sehingga mudah dilakukan pengembangan (reusable), aplikasi GUI yang dihasilkan dengan menggunakan QtDesigner pada python bersifat dinamis dan berbasis event yang membuat aplikasi menjadi responsif. Pembuatan aplikasi GUI menggunakan python semakin mudah dengan adanya QtDesigner yaitu kelas-kelas dalam bahasa pemrograman python yang bersifat event handler yang cocok untuk aplikasi GUI. Salah satu contoh aplikasi GUI yang akan dibuat menggunakan QtDesigner berbasis bahasa pemrograman python adalah sistem login pada aplikasi.
\end{abstract}

Kata Kunci: Login; GUI; Python; Event Handler; QtDesigner

\section{PENDAHULUAN}

Semakin banyak bahasa pemrograman untuk membuat aplikasi GUI. Salah satunya yaitu bahasa pemrograman python. Keunggulan menggunakan bahasa pemrograman python yaitu bersifat sederhana dan fleksibel sehingga mudah dilakukan pengembangan (reusable), aplikasi GUI yang dihasilkan dengan menggunakan QtDesigner pada python bersifat dinamis dan berbasis event yang membuat aplikasi menjadi responsif. Pembuatan aplikasi GUI menggunakan python semakin mudah dengan adanya QtDesigner yaitu kelas-kelas dalam bahasa pemrograman python yang bersifat event handler yang cocok untuk aplikasi GUI.

QtDesigner merupakan perangkat perancangan visual yang dapat dipakai untuk menciptakan GUI dengan cepat dengan teknik drag dan drop tanpa perlu menulis satu baris kode. QtDesigner memiliki beberapa widget dengan level yang berbeda yaitu Qdialog, Qwidget dan QmainWindow. Berikut tampilan halaman QtDesigner dapat dilihat seperti gambar 1. 


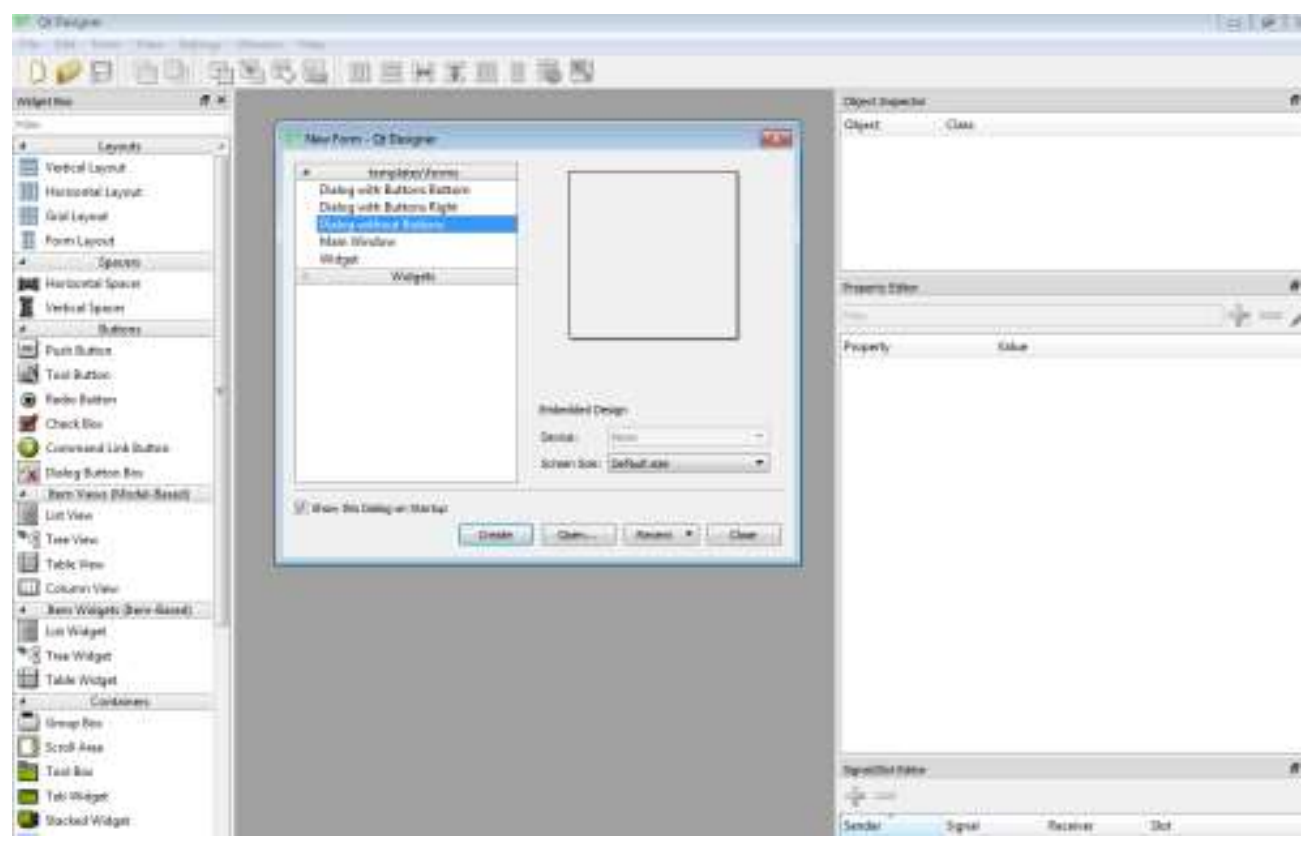

Gambar 1. Tampilan QTDesigner

Setiap aplikasi GUI memiliki widget level-atas dan sejumlah widget sebagai widget anaknya. Widget level-atas dapat berupa QDialog, QWidget, atau QMainWindow, tergantung dari template yang Anda perlukan. Jika Anda ingin menciptakan sebuah aplikasi berdasar template dialog, maka widget level-atas yang akan diwarisi adalah QDialog. Sama halnya, untuk menciptakan sebuah aplikasi berdasar template Main Window, widget level-atas akan berupa QMainWindow, dan untuk menciptakan aplikasi berdasar template widget, Anda perlu mewarisi kelas QWidget. Seperti yang telah disebutkan, widget-widget lain yang dipakai untuk GUI dinamakan dengan widget anak. Dengan menggunakan QTDesigner maka akan mempermudah pembuatan aplikasi login yang berbasis GUI dengan menggunakan bahasa pemrograman python.

\section{KERANGKA TEORI}

\subsection{Aplikasi GUI}

Menurut Lastiansah (2012), user interface adalah cara program dan pengguna berinteraksi. Istilah user interface terkadang digunakan sebagai pengganti human computer interaction (HCI) dimana semua aspek dari interaksi pengguna dan komputer. Graphical User Interface (GUI) adalah mekanisme interaksi utama antara perangkat dan pengguna untuk memilih berbagai jenis tindakan. Apa yang berinteraksi dengan pengguna adalah kumpulan elemen yang disebut objek seperti tombol dan icon. Mereka bisa dilihat, didengar, disentuh, atau dirasakan. Objek selalu terlihat oleh pengguna dan digunakan untuk melakukan tugas. Contoh interaksi yang dilakukan yang dilakukan pengguna dalam sistem graphic user interface (GUI) meliputi mengakses dan memodifikasi dengan menunjuk, memilih, dan memanipulasi (Wilbert O. Galitz, 2002: 4).

\subsection{QTDesigner}

Qt Designer adalah antarmuka grafis yang diisi dengan widget Qt dan alat lain yang digunakan untuk membangun GUI. Menggunakan drag aplikasi Qt Designer dan drop interface, Anda dapat membuat dan menyesuaikan dialog Anda sendiri, jendela, dan Widget (Willman, Joshua M, 2020). 


\subsection{Python}

Python adalah bahasa pemrograman yang fleksibel dan sederhana yang didefinisikan dalam dokumen-dokumennya sebagai berikut (Nosrati, 2011). Python adalah sebuah bahasa pemrograman dinamis yang sering digunakan dalam pengembangan aplikasi pada berbagai domain. Hal ini memungkinkan suatu program ditulis dalam beberapa pendekatan sekaligus. Misalnya, antar muka grafis dibuat dalam bentuk orientasi objek, sedangkan pemrosesan dalam bentuk fungsional atau prosedural. Bahasa pemrograman Python memiliki beberapa fitur yang dapat digunakan oleh pengembang perangkat lunak. Berikut adalah beberapa fitur yang ada pada bahasa pemrograman Python (Lutz, 2010):

1. Multi Paradigm Design

2. Open Source

3. Simplicity

4. Library Support

5. Portability

6. Extendable

7. Scalability

\section{METODOLOGI}

Konsep penelitian mempunyai beberapa tahap dan menggunakan metode pengembangan sistem seperti yang tertera pada gambar 2.

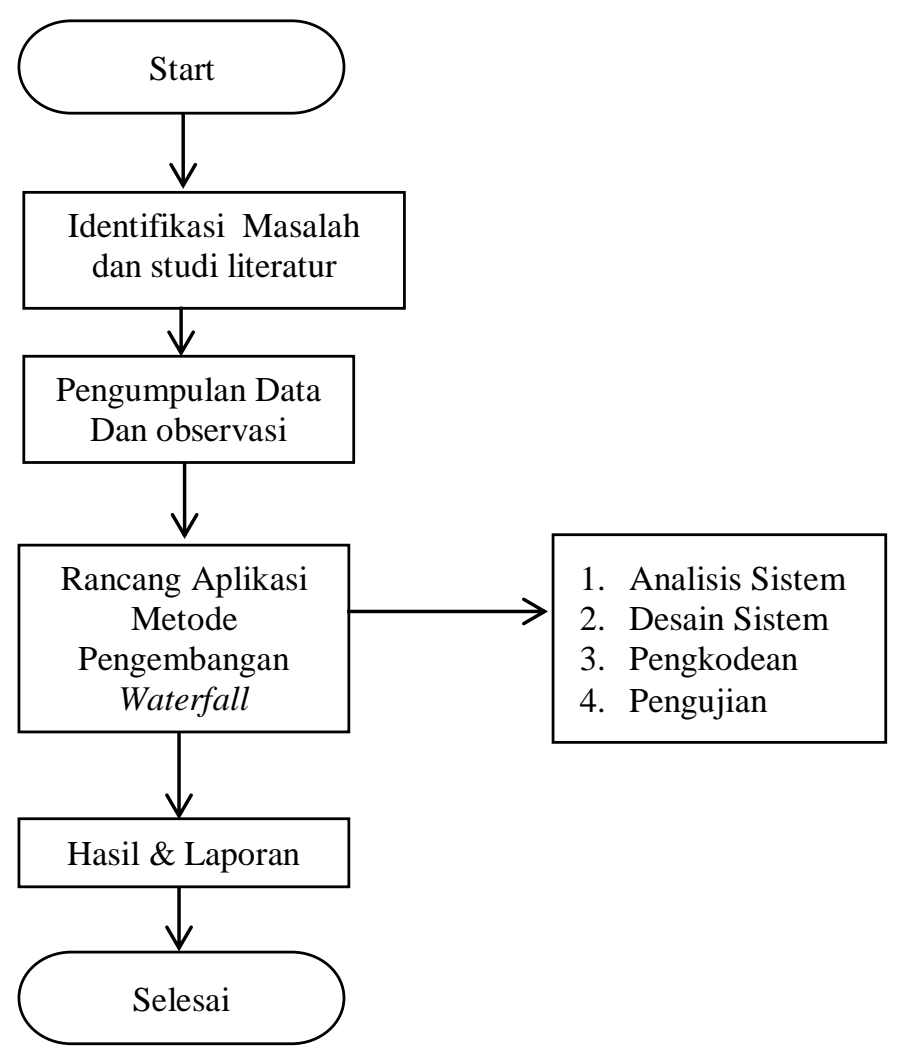

Gambar 2. Metode Pengembangan Sistem 
a. Identifikasi Masalah dan Studi Literatur

Dalam penelitian hal pertama yang dilakukan adalah mengidentikasi masalah. Identifikasi masalah adalah proses penelitian yang penting karena dapat menentukan kualitas penelitian yang dilakukan dan untuk merumuskan permasalahan yang akan menjadi latar belakang dalam objek penelitian yang dilakukan. Masalah yang diidentifikasi adalah bagaimana membuat aplikasi login menggunakan QTDesigner.

b. Pengumpulan Data dan Observasi

Setelah menyelesaikan identifikasi masalah lalu melanjutkan ke tahap berikutnya yaitu pengumpulan data. Pengumpulan data ini dilakukan dengan cara studi pustaka yaitu mengumpulkan dan mempelajari dari buku buku / jurnal yang ada agar dapat menemukan masalah yang sedang diteliti dan mengobservasi langsung melalui pengamatan model-model aplikasi login yang sering digunakan.

c. Perancangan Aplikasi dengan Metode Pengembangan Waterfall

Tahapan ini dimulai dari analisis sistem, desain sistem, pengkodean dan pengujian.

d. Hasil \& Laporan

Setelah melakukan tahap - tahap diatas maka tahap yang terakhir dalam penelitian mendapatkan sebuah hasil dari menyelesaikan sebuah masalah yang diteliti yaitu pembuatan aplikasi login berbasis GUI menggunakan QTDesigner.

Metode yang digunakan dalam penelitian ini adalah metode waterfall. Metode waterfall termasuk metode penelitian yang klasik biasa disebut juga dengan life cycle classic. Pada pengembangan penulis menngunakan metode Air terjun (waterfall). Menurut Rosa dan M. Shalahuddin (2018) Model SDLC air terjun (waterfall) sering juga disebut model sekuensial linier (sequential linier) atau alur hidup klasik (classic life cycle). Proses tersebut digambarkan dalam gambar 3.

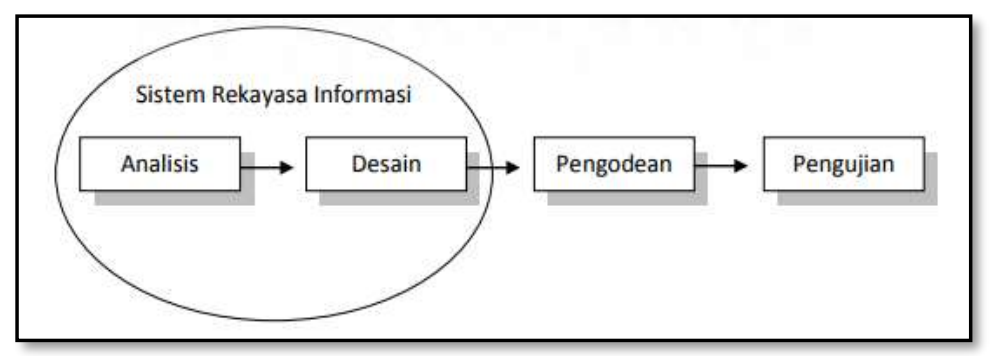

Gambar 3. Metode Waterfall

(Sumber: Rosa dan M. Shalahuddin (2018))

Langkah-langkah penelitian dalam metode waterfall:

1. Analisis kebutuhan perangkat lunak

Proses analisis kebutuhan mengidentifikasi kebutuhan apa saja yang dibutuhkan oleh perangkat lunak. Kebutuhan tersebut meliputi kebutuhan data, kebutuhan software, kebutuhan hardware dan kebutuhan brainware.Sedangkan software yang dibutuhkan untuk membuat aplikasi login berbasis GUI adalah Anaconda, XAMPP dan notepad++. kebutuhan brainware yaitu user.

2. Desain

Proses desain merupakan hasil dari proses analisis yang mulai diterapkan untuk pembuatan perangkat lunak sesuai dengan kebutuhan yang sudah diketahui. Desain meliputi desain sistem dan desain interface aplikasi login yang akan dibuat. 
3. Pengkodean

Pengkodean yaitu kode program mulai dibuat berdasarkan desain interface yang sudah dibuat. Ide - ide yang ada didesain mulai dikonversi ke dalam program.

4. Pengujian

pengujian dilakukan dengan pengujian beta untuk mengetahui apakah aplikasi login yang sudah dibuat layak dan dapat diterima oleh user atau tidak.

\section{HASIL DAN PEMBAHASAN}

1. Analisis kebutuhan aplikasi login

a) Data yang dibutuhkan dalam pembuatan aplikasi login adalah data user yaitu alamat email dan password.

b) Kebutuhan hardware yaitu perangkat keras yang digunakan dalam pembuatan aplikasi login.

c) Kebutuhan software untuk membuat aplikasi login yaitu Anaconda, XAMPP dan notepad++

2. Desain

Sebelum membuat aplikasi login, dibuat desain perancangan untuk memudahkan proses desain. Perancangan interface dapat dilihat pada gambar 4.

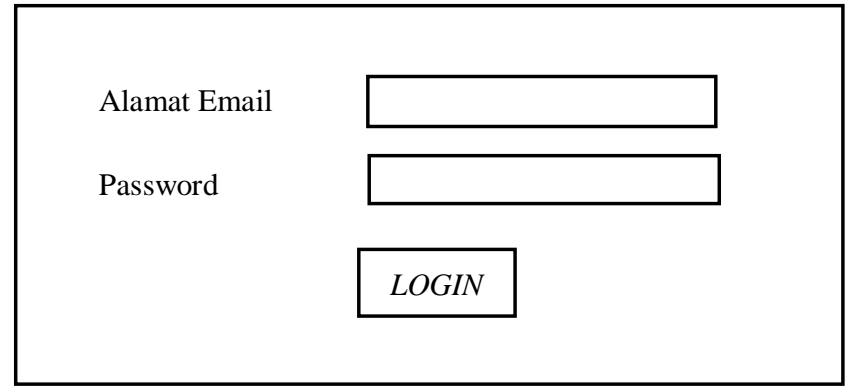

Gambar 4. Perancangan Form Login

Hasil dari perancangan implementasikan menggunakan QtDesigner dan widget akan tampak seperti pada gambar 5.

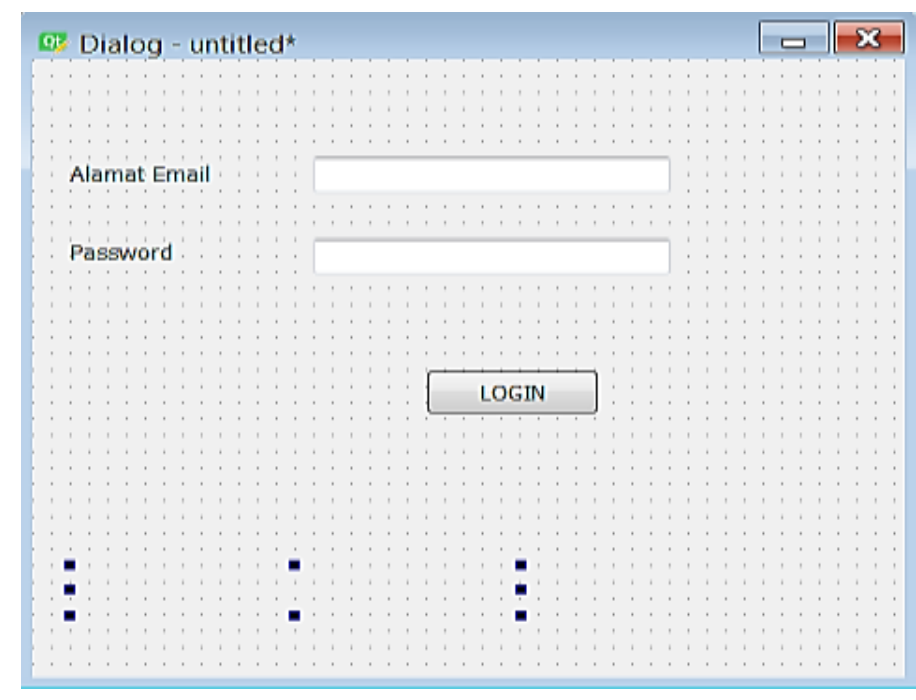

Gambar 5. Implementasi Form Login 
Berikut hasil implmentasi dari form ubah password yang berfungsi untuk merubah password seperti pada gambar 6.

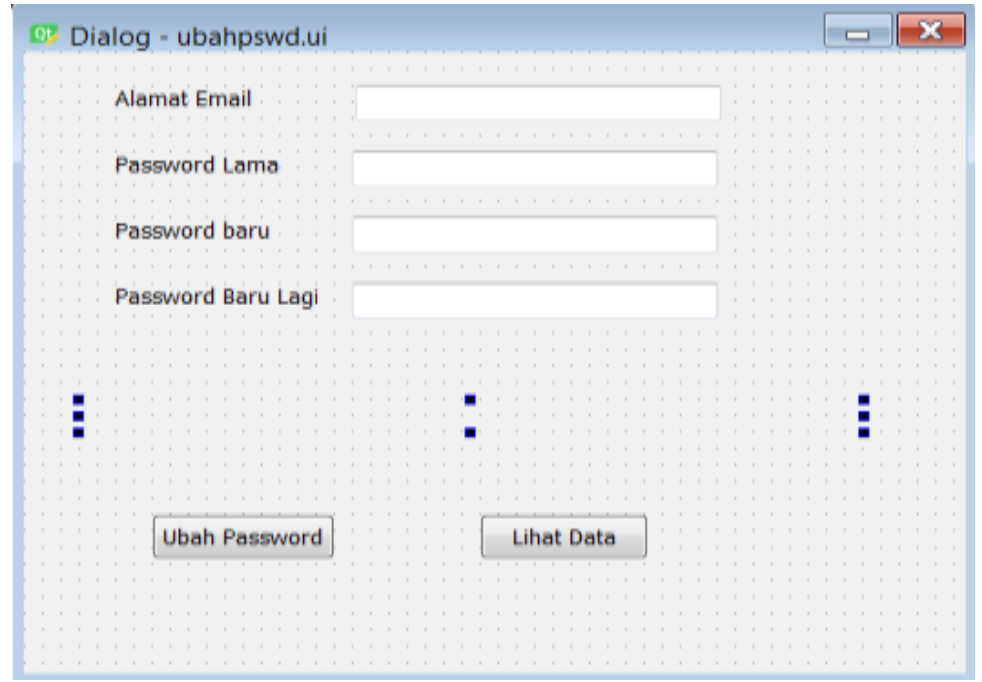

Gambar 6. Implementasi Form Login

\section{Pengkodean}

Hasil dari pengkodean untuk form tampilkan data dapat dilihat pada gambar 7.

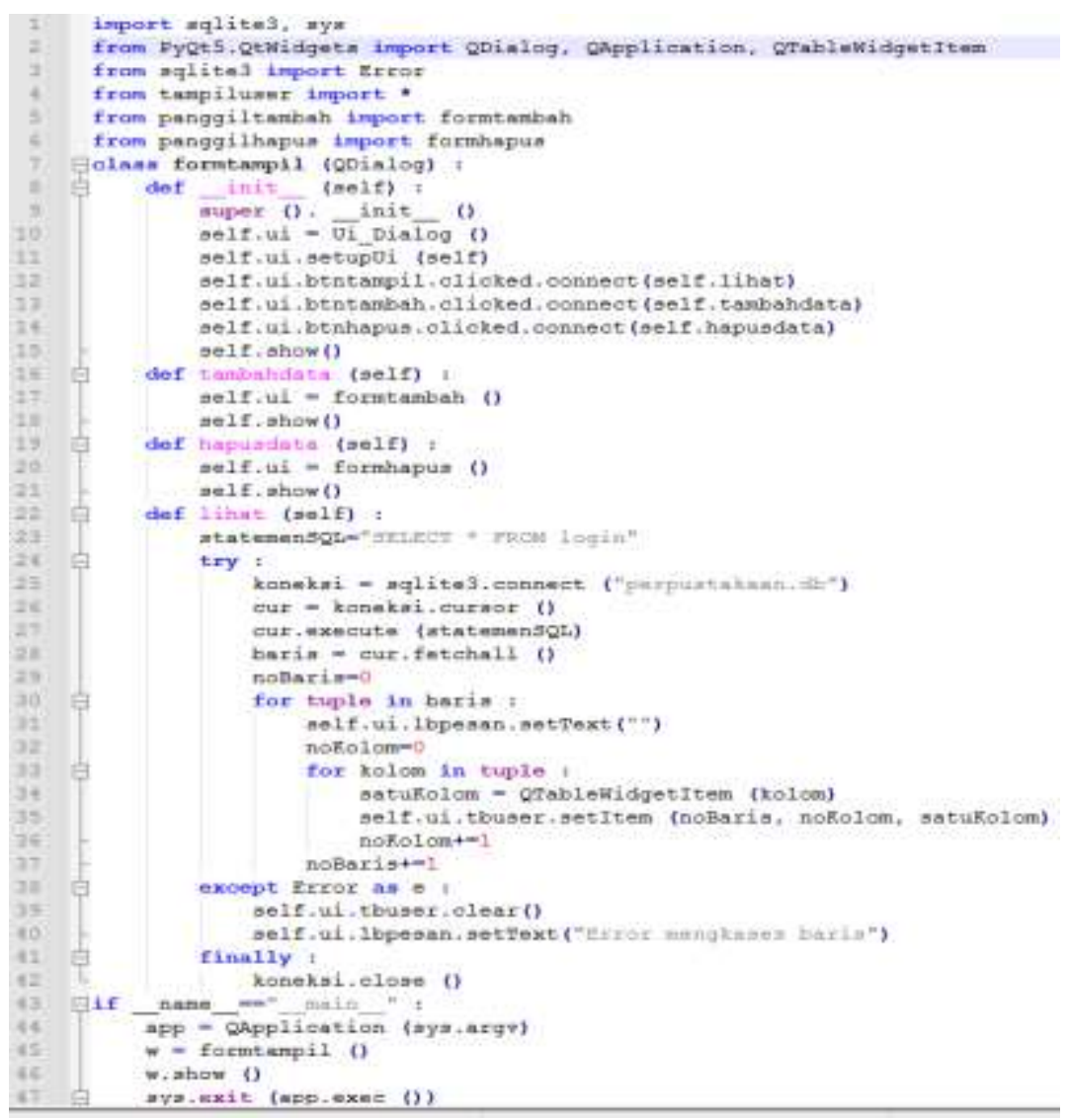

Gambar 7. Koding untuk Form Tampilkan Data 
Berikut merupakan tampilan form untuk menampilkan data serta menambah dan menghapus data yang dapat dilihat pada gambar 8 . sesuai dengan koding diatas.

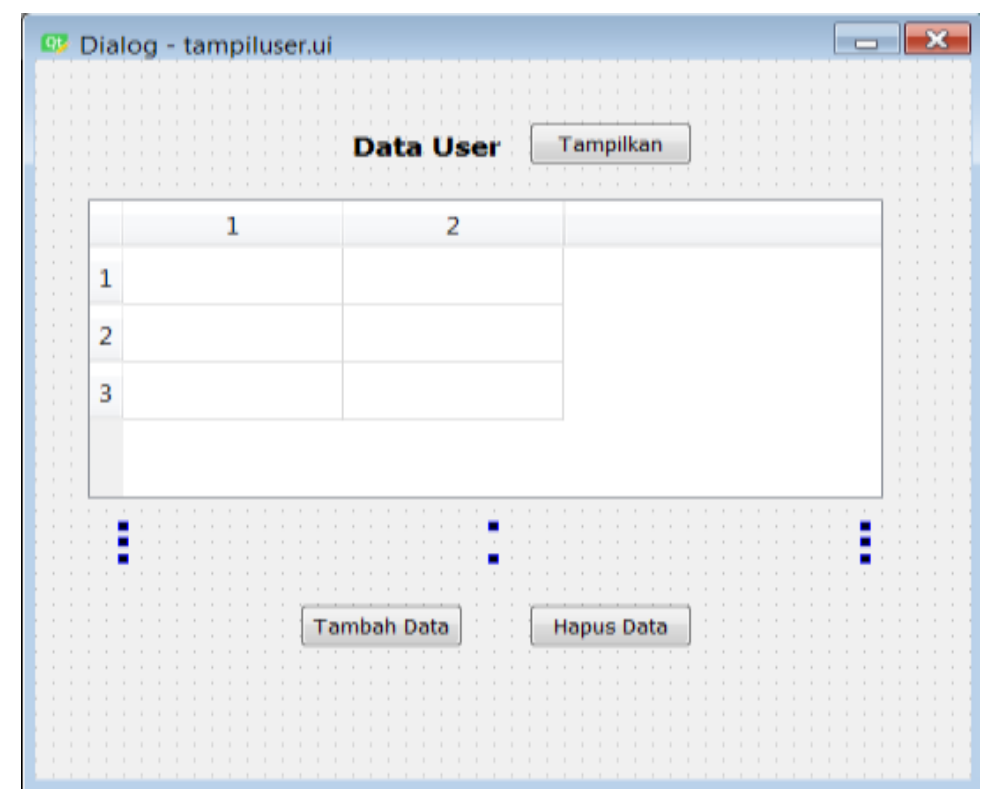

Gambar 7. Form Lihat Data

\section{Pengujian}

Perhitungan kuesioner menggunakan Skala Likert. Menurut Sugiyono (2015), skala likert adalah skala yang digunakan untuk mengukur presepsi, pendapat atau sikap seorang atau kelompok mengenai sebuah peristiwa atau fenomena sosial, berdasarkan definisi operasional yang telah ditetapkan oleh peneliti.

Tabel 1. Tabel Bobot Nilai

\begin{tabular}{cc}
\hline Skala Penilaian & Bobot Nilai \\
\hline Sangat Setuju & 5 \\
Setuju & 4 \\
Netral & 3 \\
Tidak Setuju & 2 \\
Sangat Tidak Setuju & 1 \\
\hline
\end{tabular}

Tabel 2. Tabel Bobot Hasil

\begin{tabular}{cc}
\hline Jawaban & Keterangan \\
\hline $0 \%-19,99 \%$ & Sangat Tidak Setuju \\
$20 \%-39,99 \%$ & Tidak Setuju \\
$40 \%-59,99 \%$ & Netral \\
$60-79,99 \%$ & Setuju \\
$80-100 \%$ & Sangat Setuju \\
\hline
\end{tabular}

Untuk menghasilkan interpretasi, menggunakan rumus:

$$
\text { Rumus Index } \%=\frac{\text { Total Skor }}{Y} \times 100 \%
$$

Keterangan :

Total Skor $=$ Jumlah responden $\mathrm{x}$ bobot nilai skala likert

$\mathrm{Y}=$ Jumlah total responden $\mathrm{x}$ skor tertinggi 
Tabel Presentasi Nilai Jumlah responden ada 5 orang dengan jumlah pertanyaan 7 pertanyaan. Dari hasil perhitungan kuesioner didapatkan presentase sebagai berikut:

Tabel 3. Perolehan Nilai Total Kuesioner

\begin{tabular}{|c|c|c|c|c|c|c|}
\hline \multirow{2}{*}{ No } & \multirow{2}{*}{ Aspek - aspek } & \multicolumn{5}{|c|}{ Penilaian } \\
\hline & & SS & $\mathrm{S}$ & $\mathrm{N}$ & TS & STS \\
\hline 1. & $\begin{array}{l}\text { Aplikasi login ini } \\
\text { memberikan informasi } \\
\text { dengan kebutuhan. }\end{array}$ & 3 & 2 & 0 & 0 & 0 \\
\hline 2. & $\begin{array}{l}\text { Aplikasi login ini dapat membatasi } \\
\text { pengguna dan memberikan hak } \\
\text { akses yang terbatas. }\end{array}$ & 2 & 3 & 0 & 0 & 0 \\
\hline 3. & $\begin{array}{l}\text { Aplikasi login ini memiliki } \\
\text { keamanan yang baik. }\end{array}$ & 3 & 1 & 1 & 0 & 0 \\
\hline 4. & $\begin{array}{l}\text { Tampilan dalam aplikasi login ini } \\
\text { sudah menarik. }\end{array}$ & 2 & 3 & 0 & 0 & 0 \\
\hline 5. & $\begin{array}{l}\text { Fungsi tombol - tombol navigasi } \\
\text { dalam aplikasi login sudah } \\
\text { berfungsi dengan baik. }\end{array}$ & 1 & 4 & 0 & 0 & 0 \\
\hline 6. & $\begin{array}{l}\text { Saya mudah dalam menggunakan } \\
\text { aplikasi login ini. }\end{array}$ & 3 & 2 & 0 & 0 & 0 \\
\hline 7. & $\begin{array}{l}\text { Saya dapat memperoleh informasi } \\
\text { data user dengan cepat dan tepat. }\end{array}$ & 1 & 4 & 0 & 0 & 0 \\
\hline & TOTAL & 15 & 19 & 1 & 0 & 0 \\
\hline
\end{tabular}

Pehitungan Akhir :

Total Skor $\quad=$ Total (jumlah responden $\mathrm{x}$ bobot)

$$
\begin{aligned}
& =(15 \times 5)+(19 \times 4)+(1 \times 3)+(0 \times 2)+(0 \times 1) \\
& =75+76+3+0+0 \\
& =154
\end{aligned}
$$

Skor Tertinggi $=$ Bobot nilai tertinggi $\mathrm{x}$ Jumlah Responden $\mathrm{x}$ Jumlah Pertanyaan

$$
\begin{aligned}
& =5 \times 5 \times 7 \\
& =155 \\
\text { Rumus Index \% } & =\text { Total Skor } / \text { Skor Tertinggi }(Y) \times 100 \\
& =154 / 155 \times 100 \\
& =99,3 \%
\end{aligned}
$$

\section{KESIMPULAN}

Aplikasi login dapat dibuat menggunakan QTDesigner Python dan aplikasi layak untuk digunakan. Hal ini dibuktikan dengan hasil UAT yang menunjukkan hasil index 99,3\%.

\section{DAFTAR PUSTAKA}

A. S., Rosa dan Shalahuddin, M., 2018. Rekayasa Perangkat Lunak Terstruktur dan Berorientasi Objek. Bandung: Informatika. 
B. Herry Suharto., Wijono, Soesilo., 2006. Membangun Aplikasi Menggunakan Qt Designer dengan Database PostgreSQL/MySQL. Yogyakarta: Penerbit Andi.

Lutz, M., 2010. Programming Python. Fourth Edition ed. Sebastopo: O’Reilly Media, Inc.

Lastiansah, Sena., 2012. Pengertian User Interface. Jakarta: Elex Media Komputindo.

Nosrati, M., 2011. Python: An appropriate language for real world programming. World Applied Programming

Vol. 1 No.2 Hal. 110-117.

Willman, Joshua M., 2020. Beginning PyQt (A Hands-on Approach to GUI Programming). doi:10.1007/978-1-48425857-6.

Wilbert O. Galitz., 2007. The Essential Guide to User Interface Design. Canada: Wiley Publishing,Inc. 